\title{
Patellofemoral pain in athletes: clinical perspectives
}

This article was published in the following Dove Press journal:

Open Access Journal of Sports Medicine

9 October 2017

Number of times this article has been viewed

\author{
Farzin Halabchi ${ }^{1,2}$ \\ Maryam Abolhasani ${ }^{1,2}$ \\ Maryam Mirshahi ${ }^{1,2}$ \\ Zahra Alizadeh ${ }^{1,2}$
}

'Sports Medicine Research Center, Neuroscience Institute, Tehran University of Medical Sciences, Tehran, Iran; ${ }^{2}$ Department of Sports and Exercise Medicine, Tehran University of Medical Sciences, Tehran, Iran
Correspondence: Zahra Alizadeh Sports Medicine Research Center, No. 7, Ale-ahmad Highway, Opposite of the Shariati Hospital, 14395-578, Tehran, Iran Tel +98 $2188630227-8$

Fax +98 21 88003539

Email z_alizadeh@tums.ac.ir
Abstract: Patellofemoral pain (PFP) is a very common problem in athletes who participate in jumping, cutting and pivoting sports. Several risk factors may play a part in the pathogenesis of PFP. Overuse, trauma and intrinsic risk factors are particularly important among athletes. Physical examination has a key role in PFP diagnosis. Furthermore, common risk factors should be investigated, such as hip muscle dysfunction, poor core muscle endurance, muscular tightness, excessive foot pronation and patellar malalignment. Imaging is seldom needed in special cases. Many possible interventions are recommended for PFP management. Due to the multifactorial nature of PFP, the clinical approach should be individualized, and the contribution of different factors should be considered and managed accordingly. In most cases, activity modification and rehabilitation should be tried before any surgical interventions.

Keywords: anterior knee pain, sport, rehabilitation, runners' knee

\section{Introduction}

Pain in retropatellar and peripatellar regions is clinically referred to as patellofemoral pain (PFP). However, there is not a clear definition. The term patellofemoral pain syndrome (PFPS) is still a "wastebasket", which includes different entities. ${ }^{1}$ It is a very common complaint in general population, particularly in young adult and adolescent athletes who participate in jumping, cutting and pivoting sports. ${ }^{2-4}$ It is reported that almost $25 \%-30 \%$ of all injuries seen in a sports medicine clinic ${ }^{5,6}$ and up to $40 \%$ of clinical visits for knee problems $s^{4,7}$ are attributed to PFP. PFP accounts for $33 \%$ and $18 \%$ of all knee injuries in female and male athletes, respectively. ${ }^{9,10}$ It is also one of the most common overuse injuries among different sports disciplines such as basketball, ${ }^{11,12}$ volleyball ${ }^{13,14}$ and running, ${ }^{14-17}$ and a prevalence rate of between $13 \%$ and $26 \%$ is reported in females participating in soccer, volleyball, running, fencing and rock climbing. ${ }^{14}$ Incidence of PFP among adolescent females and young adult women is 2-10 times more than in their male counterparts. ${ }^{10,17,18}$ PFP symptoms may lead to limitation of sport and physical activities in $74 \%$ of patients or cause sports cessation. ${ }^{19-21}$

Current literature contradicts the hypothesis that PFP has a benign and selflimiting course; in contrast, PFP is a refractory condition which may persist for many years and is a likely contributor to long-term patellofemoral osteoarthritis, especially in cases of adolescent anterior knee pain. ${ }^{21-24}$ Otherwise, some young PFP patients may have risk factors that place them at future risk for anterior cruciate ligament injury. ${ }^{25}$ 


\section{Terminology}

Despite different terms proposed to describe this condition, such as anterior knee pain or syndrome, PFP, patellofemoral pain syndrome, patellofemoral arthralgia, chondromalacia patellae, lateral patellar compression syndrome and patellalgia, ${ }^{26}$ a recent consensus statement from the Fourth International Patellofemoral Pain Research Retreat recommended PFP as the preferred term. However, it does not consider how nonpainful joint conditions could be a precursor to pain development and does not include symptoms such as crepitus, and its main focus is on the "pain" aspect of the disorder. ${ }^{27,28}$

\section{Definition}

PFP is characterized by pain in the peripatellar/retropatellar area that aggravates with at least one activity that loads the patellofemoral joint during weight bearing on a flexed knee (e.g., squatting, stair climbing, jogging/running and hopping/ jumping). Additional nonessential criteria include crepitus or grinding sensation in the patellofemoral joint during knee flexion movements, tenderness on patellar facet palpation, small effusion and pain on sitting, rising on sitting or straightening the knee following sitting. ${ }^{27-29}$

\section{Risk factors}

As an overuse injury, several risk factors may play a role in the pathogenesis of PFP. These risk factors are classified as intrinsic and extrinsic risk factors. ${ }^{3}$

Extrinsic risk factors are related to factors outside the body, such as the type and volume of sports activity, environmental conditions and the surface and equipment used. Intrinsic risk factors are attributed to individual characteristics. $^{3}$

Expert consensus statements suggest biomechanical risk factors explained by anatomic location relative to the knee. These factors include proximal (upper femur, hip and trunk), local (in and around the patella and the patellofemoral joint) and distal (lower leg, foot and ankle)..$^{6,30,31}$ These risk factors can be anatomic (increased femoral anteversion, trochlear dysplasia, patella alta and baja, excessive foot pronation and so on) or biomechanical (muscle tightness or weakness, generalized joint laxity, gait abnormalities and so on).

Some of these proposed intrinsic risk factors and clinical tests for their assessment have been shown in Table 1.

\section{History}

Patients with PFP typically describe diffuse ill-defined pain behind, underneath or around the patella, usually with activities such as squatting, running and stair ascent or descent..$^{32,34,100}$ If asked to point to the site of pain, patients may place their hands over the anterior aspect of the knee or draw a circle with their fingers around the patella (the circle sign). The symptoms are usually of gradual onset, although some of them may be acute and caused by trauma. Pain may be unilateral or bilateral and is usually described as achy, but may be sharp. ${ }^{32,34}$ Sometimes, patients report stiffness or pain on prolonged sitting with the flexed knees (the theater or moviegoer sign). ${ }^{34}$

Patients may occasionally report the knee giving way or buckling. This perceived instability may be due to inhibitory effect of pain on the suitable contraction of the quadriceps, but it should be differentiated from instability originating from a patellar dislocation, subluxation or ligamentous injury of the knee. ${ }^{32,101}$ Feeling of a popping or catching may be described. Locking of the joint is not characteristic of PFP and implies a meniscal tear or loose body. Occasionally, mild swelling may be present. However, it is rare to see a gross effusion seen with a traumatic knee injury. ${ }^{32,34}$

Taking history in athletes presenting with PFP may mandate some special considerations. As PFP is attributed to overuse in many cases, recent alterations in sporting activities, including any changes in the frequency, duration and intensity of training should be investigated in detail. ${ }^{34,100}$ The training program also should be appraised for errors, including increasing the exercise intensity too rapidly, inadequate recovery time and extreme hill workouts. ${ }^{32}$ It must be considered that PFP may present as an acute re-exacerbation of the chronic condition. ${ }^{100}$

Use of inappropriate or excessively worn footwear, recent heavy resistance training and conditioning activities (particularly squats and lunges) and running on altered surface or hills should also be considered. A history of knee traumatic injuries, including patellar subluxation or dislocation, or surgeries should be noted, as they may directly damage the articular cartilage or change the forces across the patellofemoral joint, resulting in PFP. ${ }^{32,34}$

\section{Physical examination}

Physical examination is the foundation of PFP diagnosis, ${ }^{102}$ but there is no definitive clinical test to diagnose PFP. ${ }^{103} \mathrm{~A}$ variety of tests have been explained to diagnose PFP. ${ }^{104,105}$ However, the common tests for PFP are not sensitive when compared with pathologic operative findings. ${ }^{104}$ Lack of sensitive tests to help rule out PFPS when negative implies that PFPS may be a diagnosis of exclusion and may be best identified after ruling out other diagnoses such as tibiofemoral osteoarthritis, plica syndrome or other masquerading 
Table I Potential intrinsic risk factors, tests for assessment and their reliability

\begin{tabular}{|c|c|c|}
\hline Potential risk factor & Tests & Reliability \\
\hline $\begin{array}{l}\text { Weakness of quadriceps muscle, } \\
\text { especially } \mathrm{VMO}^{29,32-35}\end{array}$ & $\begin{array}{l}\text { One-legged hop test. Test is performed by jumping and landing } \\
\text { on the same foot with the hands behind the back and the hop } \\
\text { distance is measured from toe. }{ }^{36} \mathrm{~A} \text { quotient (\%) between the } \\
\text { injured and noninjured legs is registered and defined as abnormal if } \\
\text { the quotient is }<85 \%{ }^{37}\end{array}$ & Good reliability ${ }^{36,38,39}$ \\
\hline $\begin{array}{l}\text { Hip muscle dysfunction } \\
\text { (particularly, the abductors and } \\
\text { external rotators })^{30,40,41}\end{array}$ & $\begin{array}{l}\text { The Trendelenburg test (for hip abductors) to assess the ability to } \\
\text { hold the pelvis level, while the subject performs a single-leg stance. } \\
\text { Lateral pelvic shift or lowering of one side of the pelvis indicates } \\
\text { weakness of hip abductors }{ }^{42,43}\end{array}$ & $\begin{array}{l}\text { Good sensitivity, good to excellent } \\
\text { specificity }\end{array}$ \\
\hline Poor core muscle endurance ${ }^{45,46}$ & $\begin{array}{l}\text { Front plank, modified Biering-Sorensen and side bridge for } \\
\text { anterior, posterior and lateral core muscle endurance }{ }^{45,47}\end{array}$ & Good reliability ${ }^{47}$ \\
\hline Tightness of hamstring $g^{3,48-50}$ & $\begin{array}{l}\text { Passive knee extension test with goniometric measurement } \\
\text { of popliteal angle. } .^{3,49} \text { Test is considered positive when a knee } \\
\text { extension angle of }>20^{\circ} \text { is measured } d^{51,52}\end{array}$ & $\begin{array}{l}\text { Excellent inter-rater and good test- } \\
\text { retest reliability }{ }^{53-55}\end{array}$ \\
\hline $\begin{array}{l}\text { Tightness of iliopsoas and } \\
\text { quadriceps }{ }^{3,48,56,57}\end{array}$ & $\begin{array}{l}\text { Modified Thomas test. }{ }^{58.59} \text { Two angles were measured for each } \\
\text { limb. Lengths of iliopsoas and quadriceps were determined by } \\
\text { measuring the angles of hip and knee flexion, respectively. Inability } \\
\text { of the opposite thigh to extend to a neutral position or drop } \\
\text { below the horizontal constitutes a positive test for iliopsoas. The } \\
\text { angle of knee flexion of }<80^{\circ} \text { determines the quadriceps shortness }\end{array}$ & $\begin{array}{l}\text { Very good to excellent inter-rater and } \\
\text { good test-retest reliability }\end{array}$ \\
\hline Tightness of iliotibial band ${ }^{60-62}$ & $\begin{array}{l}\text { Ober test. }{ }^{61-64} \text { Positive test occurs when the leg remains in an } \\
\text { abducted position (rests above the horizontal) }\end{array}$ & $\begin{array}{l}\text { Excellent intra-rater and inter-rater } \\
\text { reliability }{ }^{66}\end{array}$ \\
\hline $\begin{array}{l}\text { Tightness of gastrosoleus } \\
\text { complex }^{32,67}\end{array}$ & $\begin{array}{l}\text { Weight-bearing lunge test. }{ }^{68} \text { Test is considered positive when } \\
\text { I) the distance between the wall and the big toe measured is }<9 \mathrm{~cm} \\
\text { or } 2 \text { ) the angle made by the anterior tibia/shin to vertical is }<35^{\circ 69}\end{array}$ & $\begin{array}{l}\text { Excellent intra-rater and inter-rater } \\
\text { reliability }{ }^{69}\end{array}$ \\
\hline Excessive foot pronation ${ }^{32,70,71}$ & $\begin{array}{l}\text { FPI }-6{ }^{72,73} \text { Scores of }+6 \text { to }+9 \text { and }+9 \text { to }+12 \text { are regarded pronated } \\
\text { and highly pronated, respectively }{ }^{74}\end{array}$ & $\begin{array}{l}\text { High intra-rater and inter-rater reliability } \\
\text { among PFPS patients }{ }^{73,74}\end{array}$ \\
\hline Limb length discrepancy ${ }^{75}$ & $\begin{array}{l}\text { Gauging the distance between the anterior superior iliac spine and } \\
\text { the medial malleolus of both legs (average of two measures). Limb } \\
\text { length inequalities of }>10 \mathrm{~mm} \text { is considered clinically significant }{ }^{76}\end{array}$ & $\begin{array}{l}\text { High intra-rater and inter-rater } \\
\text { reliability } 77,78\end{array}$ \\
\hline Patellar malalignment ${ }^{34,79,80}$ & $\begin{array}{l}\text { Patellar tilt and mediolateral glide tests. } .^{34,81,82} \text { Tilt occurs when } \\
\text { the digit palpating one of the patellar borders is more anterior } \\
\text { than the other. The glide is positive when the distance from the } \\
\text { midpatella to each femoral epicondyle is not equal }\left.\right|^{81}\end{array}$ & $\begin{array}{l}\text { Fair intra-rater and poor inter-rater } \\
\text { reliability }{ }^{81,83}\end{array}$ \\
\hline Patellar hypermobility 3,34 & $\begin{array}{l}\text { Patellar mobility test, with the knee flexed } 20^{\circ}-30^{\circ} \text { and the } \\
\text { quadriceps relaxed. }{ }^{84} \text { Patellar mobility of more than three } \\
\text { quadrants suggests a hypermobile patella }{ }^{34}\end{array}$ & $\begin{array}{l}\text { Good intra-rater and variable inter-rater } \\
\text { reliability }{ }^{84}\end{array}$ \\
\hline$G J L^{3,34,85}$ & $\begin{array}{l}\mathrm{BHJMI} \text {, in which the range of scoring is between } 0 \text { and } 9 \text {, with high } \\
\text { scores denoting greater joint laxity }\end{array}$ & Good to excellent reliability ${ }^{86-88}$ \\
\hline Genu varum ${ }^{89}$ & $\begin{array}{l}\text { Goniometric measurement in a standing position and barefoot, } \\
\text { with toes placed forward and feet shoulder-width apart }{ }^{90}\end{array}$ & $\begin{array}{l}\text { Correlated well with the angle measured } \\
\text { on the full-limb radiograph (gold } \\
\text { standard) }\end{array}$ \\
\hline Abnormal trochlear morphology91 & $\begin{array}{l}\text { Measurement of sulcus angle in plain radiography (skyline or } \\
\text { tangential patellar views performed in } 25^{\circ} \text { of flexion; normal value } \\
\left.138^{\circ}, \mathrm{SD} 6^{\circ}\right)^{92} \text { or evaluation of lateral trochlear inclination, medial } \\
\text { trochlear inclination, sulcus angle and trochlear angle on the axial } \\
\text { MRI }\end{array}$ & $\begin{array}{l}\text { Excellent intraobserver and } \\
\text { interobserver reliability (ICCs of } 0.94 \\
\text { and } 0.92 \text {, respectively), }{ }^{92,93} \text { but some } \\
\text { newer evidence recommended MRI }{ }^{94}\end{array}$ \\
\hline Abnormal proprioception ${ }^{95,96}$ & $\begin{array}{l}\text { Measurement of knee joint position sense using five active tests } \\
\text { under non-weight-bearing and uni- and bilateral weight-bearing } \\
\text { conditions }{ }^{95}\end{array}$ & Good reliability ${ }^{97}$ \\
\hline $\begin{array}{l}\text { Gait abnormalities (heel strike in a } \\
\text { less pronated position and there is } \\
\text { roll over more on the lateral side) } \\
{ }^{98}\end{array}$ & $\begin{array}{l}\text { Plantar pressure measurements during walking using a foot scan } \\
\text { pressure plate }{ }^{98}\end{array}$ & Reliable (ICC: 0.75) ${ }^{99}$ \\
\hline
\end{tabular}

Abbreviations: BHJMI, Beighton and Horan Joint Mobility Index; FPI-6, Foot Posture Index-Version 6; GJL, generalized joint laxity; ICC, Intraclass Correlation Coefficient; MRI, magnetic resonance imaging; PFPS, patellofemoral pain syndrome; SD, standard deviation; VMO, vastus medialis obliques. 
conditions. ${ }^{106}$ According to the recent consensus statement from the Fourth International Patellofemoral Pain Research Retreat, anterior knee pain elicited during a squatting maneuver is the best available test, and PFP is evident in $80 \%$ of people who are positive on this test. ${ }^{103}$ Several other tests proposed for PFP have limited evidence supporting their use. Tenderness on palpation of the patellar edges is another test with limited evidence and PFP is evident in 71\%-75\% of people with this finding. ${ }^{103}$ Full range of knee motion and lack of effusion are common findings in PFP patients. ${ }^{28,103}$ Patellar grinding and inhibition tests (e.g., Clarke's test) have low sensitivity and limited diagnostic accuracy for PFP. ${ }^{103}$

In another prospective study on the diagnostic value of five common tests, the authors reported three tests of vastus medialis coordination, patellar apprehension and eccentric step to have a positive ratio. It means that positive test results increase the likelihood of PFP ${ }^{80,105}$ As an important point, clinical examination of athletes engaging in high-demanding sports may necessitate more challenging and highly dynamic tests (e.g., single leg-squat or lateral step-down tests) to reveal the subtle cases of overuse injuries.

In this part, we will describe the common clinical tests used for PFP diagnosis.

\section{Vastus medialis coordination test}

In patient's supine position, the examiner places the fist under the subject's knee and asks the patient to extend the knee slowly without pressing down or lifting away from the examiner's fist. The patient is instructed to achieve full extension (Figure 1). The test is considered positive when a lack of coordinated full extension is apparent, that is, when the patient either has difficulty smoothly achieving extension or uses the extensors or flexors of the hip to accomplish extension. A positive test may be an indicator of dysfunction of the vastus medialis obliquus muscle. ${ }^{105,107}$

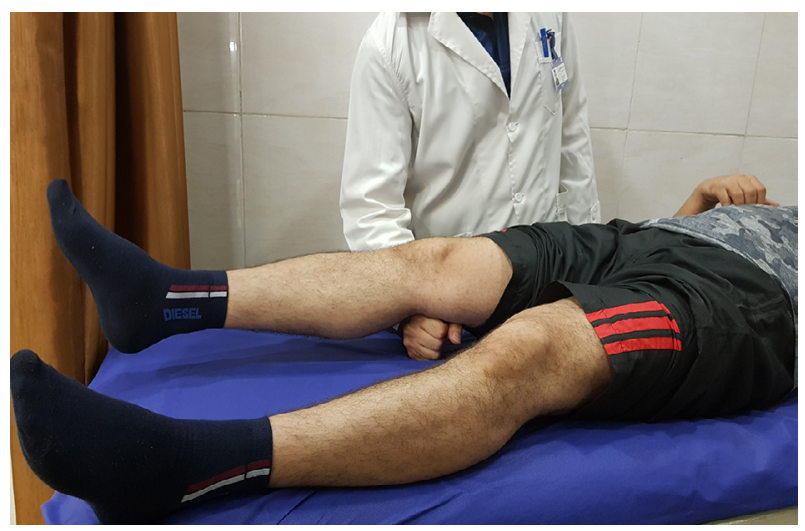

Figure I Vastus medialis coordination test.

\section{Patellar apprehension test}

The patellar apprehension test, also referred to as the Fairbanks apprehension test, is performed with the patient in supine and relaxed position. The examiner uses one hand to push the patient's patella as lateral as possible, in order to obtain a lateral patellar glide. Starting with the knee flexed at $30^{\circ}$, the examiner grasps the leg at the ankle/heel with the other hand and performs a slow, combined flexion in the knee and hip. This lateral glide is maintained throughout the test (Figure 2). The test is considered positive when it reproduces the patient's pain or when apprehension is present. ${ }^{104,105,107}$

\section{Eccentric step test}

For the eccentric step test, the patients perform the testing in bare feet. The step is $15 \mathrm{~cm}$ high or more accurately with height equal to $50 \%$ of the length of tibia. Briefly, each patient is asked to stand on the step, put hands on the hips and step down from the step as slowly and smoothly as she/he can. Patients should keep the hands on their hips throughout the test performance (Figure 3). After the patient performs the test with one leg, the procedure is repeated using the other leg. A warm-up or practice attempt is not allowed. The eccentric step test is considered positive when the patient reports knee pain during the test performance. ${ }^{105,108,109}$

\section{Waldron's test (Phases I and II)}

To do Phase I of Waldron's test, patient lies supine and the examiner presses the patella against the femur while concurrently performing a passive knee flexion with the other hand (Figure 4A). ${ }^{110}$ For Phase II, the standing patient performs a slow, full squat, again with the examiner performing a gentle compression of the patella against the femur (Figure 4B). In

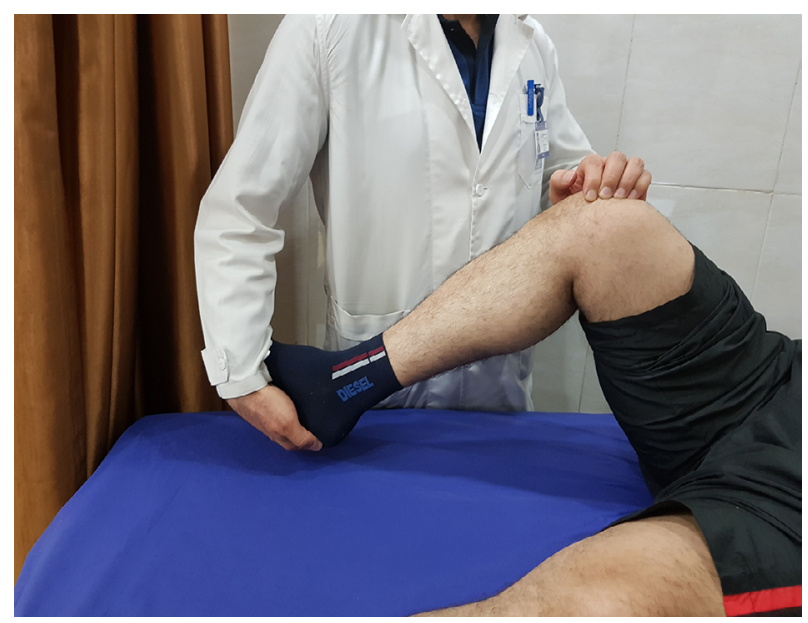

Figure 2 Patellar apprehension test. 
both phases, crepitus and pain during a particular part of the range of motion are considered signs of PFP disorders. ${ }^{105,107}$

\section{Clarke's test (or patellofemoral grinding test)}

Clarke's test is performed with the patient lying supine with both knees supported by a pad, in order to create an adequate

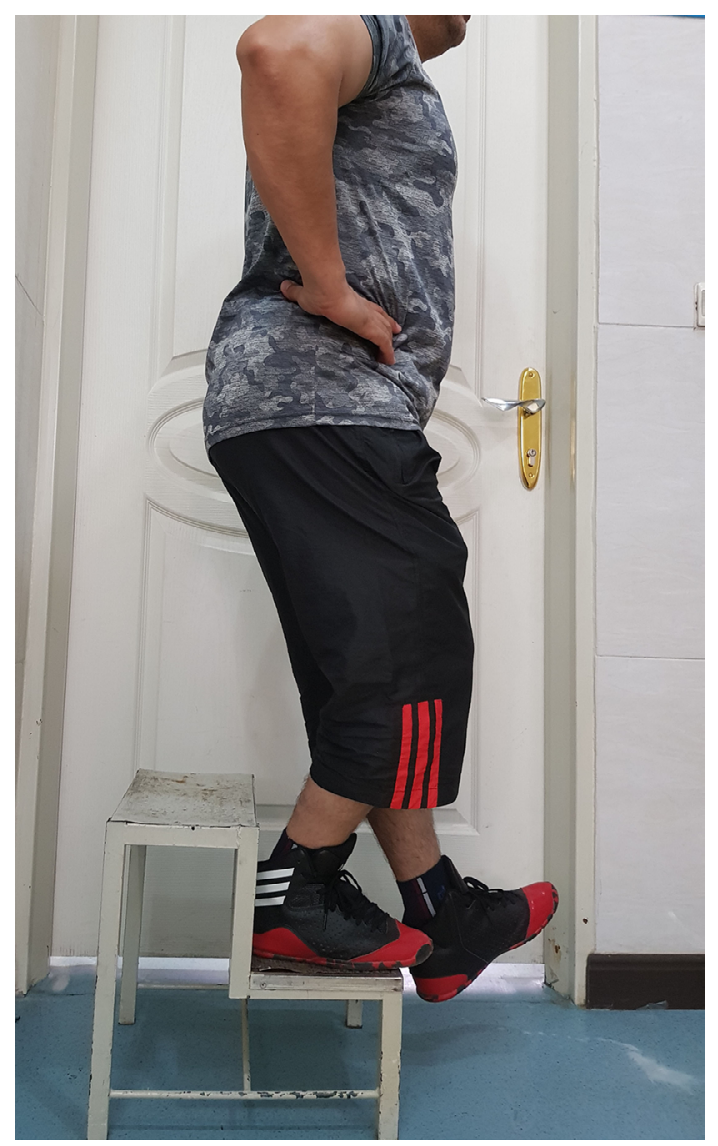

Figure 3 Eccentric step test.

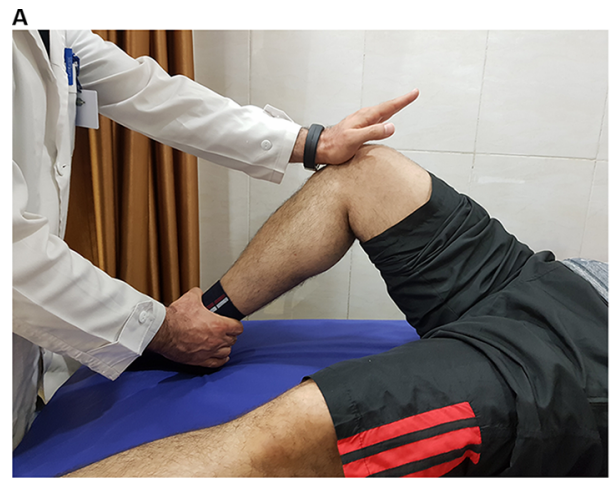

Figure 4 Waldron's test: (A) Phase I and (B) Phase II. amount of knee flexion $\left(10^{\circ}-20^{\circ}\right)$ and consequent articulation of the patella in the patellofemoral joint. ${ }^{107}$ While the patient is relaxed, the examiner presses the patella distally (with the hand on the superior border of the patella) and then requests the patient to contract the quadriceps muscle (Figure 5). ${ }^{104}$ If the patient's pain is reproduced during the test, the test will be considered positive. However, as explained before, Clarke's test is not recommended as a diagnostic test for PFP due to the lack of clarity regarding its definite mechanics of application, uncertainty regarding what represents a positive test and its poor diagnostic accuracy. ${ }^{26}$

\section{Standard step-down test}

Standard step-down test is very similar to eccentric step test, except that the patient should stand with arms folded across the chest and be instructed to squat down 5-10 times consecutively in a slow and controlled manner until the heel touches the floor, maintaining their balance at a rate of approximately one squat per $2 \mathrm{~s}$ (Figure 6). Scoring of the deviations in the trunk, pelvis, hip and knee reveals the onset timing of the

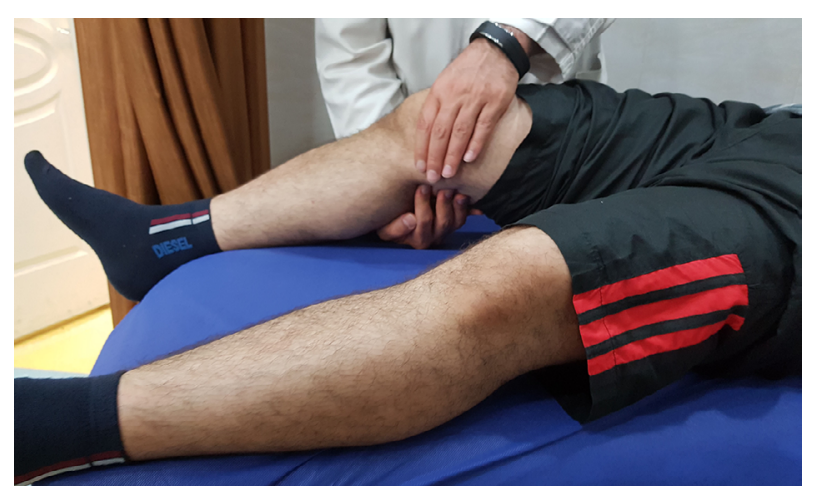

Figure 5 Clarke's test.

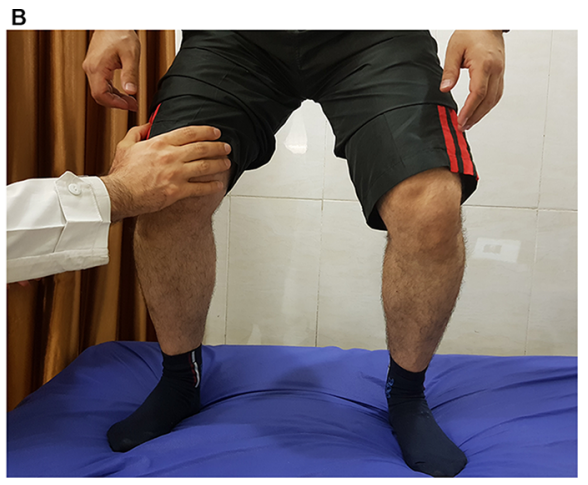




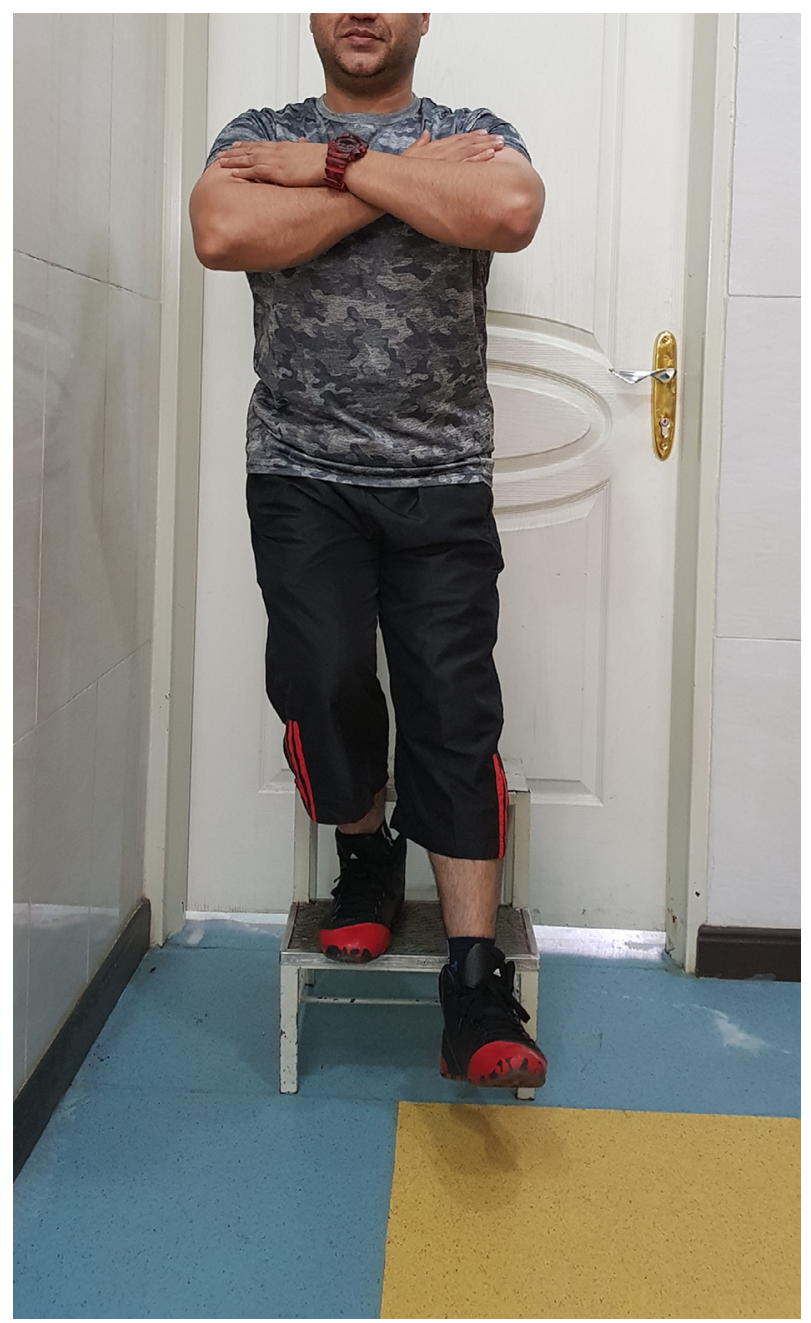

Figure 6 Standard stepdown test.

anterior gluteus medius, hip abduction torque and decreased lateral trunk strength. ${ }^{100}$ Excellent inter-rater $(k=0.80)$ and intra-rater $(k=0.80)$ reliability has been reported for this test. ${ }^{111}$

\section{Lateral step-down test}

The lateral step-down test is a modification of standard step-down test, in which the movement is in the lateral direction. ${ }^{12}$ Instructions for the lateral step-down test are as follows: The patient is requested to stand with the involved leg on a $15 \mathrm{~cm}$ step. This will require most to bend the knee at about $60^{\circ}$ during the test. The patient is asked to reach down and touch the opposite, noninvolved heel to the ground, then return to the starting position. The patient should be rated on the criteria, including arm strategy, trunk alignment, pelvis plane, knee posture and steadiness. ${ }^{100}$

\section{Single-leg squat}

Single-leg squat is a test of dynamic hip and quadriceps strength in the examination. This maneuver imposes higher

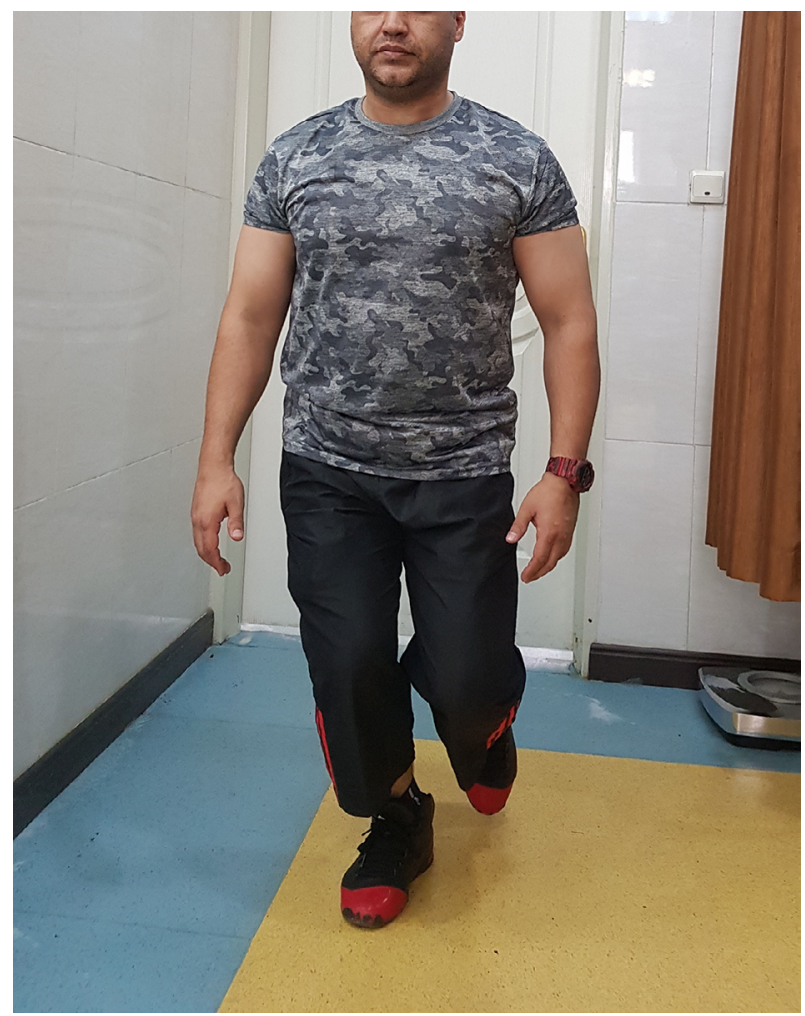

Figure 7 Single-leg squat.

mechanical demands than a bilateral squat, which may induce compensatory movements such as knee valgus (Figure 7). This may partially be due to the smaller base of support and increased amounts of dynamic control that are needed in all planes during the single limb squat. Compared to controls, patients with PFP showed increased ipsilateral trunk lean, contralateral pelvic drop, hip adduction and knee abduction during a single-leg squat. ${ }^{100,113}$

As noted earlier, assessment of common intrinsic risk factors of PFP is crucial in physical examination and for planning proper rehabilitation program (Table 1). An illustrated description of the simple clinical methods to assess these common risk factors has been published. ${ }^{114}$

\section{Imaging}

The diagnosis of PFPS is mainly clinical, and diagnostic imaging is not required for many patients. However, plain radiography may be indicated in the following cases: a history of recent trauma, dislocation or surgery, joint effusion, patients older than 50 years (to assess for patellofemoral osteoarthritis), patients who are skeletally immature (to rule out other causes such as osteochondritis dissecans, physeal injury or bone tumors), suspected cases of bipartite patella, loose bodies and occult fractures, and those who do not demonstrate improvement after several weeks of conservative 
treatment. Radiography is an adjunct to history and physical examination. ${ }^{32,34}$ Nevertheless, radiographic findings may not correlate well with clinical complaints, and often, the symptomatic side is difficult to differentiate from the asymptomatic side. ${ }^{80}$

The diagnosis of PFPS depends primarily on the history and physical exam, but radiography is an adjunct to them. It is essential to obtain radiographs in the athlete who has apparent PFP and does not reveal improvement after several weeks of conservative treatment, or if there has been a severe malalignment or history of recent trauma. ${ }^{32}$ The standard radiographic series for assessment of patellofemoral problems includes weight-bearing anterior-posterior (A-P), weight-bearing lateral, and axial or Merchant views in $20^{\circ}-45^{\circ}$ of knee flexion..$^{32,115}$

Standard A-P radiograph is useful to identify accessory ossification centers, degenerative joint disease and bone tumors. ${ }^{32}$ The lateral view is most valuable for the assessment of patellar height.

Axial views allow evaluation of degenerative changes in the patellofemoral joint, osteochondritis dissecans of the patella, patellar morphology, dysplasia of the trochlear groove, and accessory ossification centers and ectopic calcifications in the retinaculum. ${ }^{32}$ However, some studies recommend straight lateral projection X-ray for evaluation of the trochlear configuration and subtle patellar tracking abnormalities. ${ }^{116}$ Where osteoarthritis seems to dominate in the patellofemoral compartment, the radiographic features of patellofemoral osteoarthritis include joint space narrowing, subchondral sclerosis, and cysts and osteophytes at the posterior margins of the patella. ${ }^{115}$

Computed tomography and magnetic resonance imaging (MRI) are not needed for most patients with PFP. MRI is the best tool for evaluation of malalignment, trochlear dysplasia, patella tilt and articular chondral injuries. ${ }^{94,117,118}$ MRI can be useful in detecting, loose bodies, patellar stress fractures and bone marrow edema, which is suggestive of patellar subluxation or dislocation. ${ }^{34}$ Cartilage loss and subchondral sclerosis, edema and cystic changes at the patellar and trochlea surfaces are the main findings in patellofemoral osteoarthritis on MRI. ${ }^{115}$

\section{Differential diagnosis}

A systematic knee and hip examination is necessary, particularly in children and adolescents, to rule out other causes of anterior knee pain. Anteromedial knee pain, particularly in adolescents, can be a consequence of plica syndrome. ${ }^{119}$ Pain localized to the inferior patellar pole may suggest patellar tendinopathy in adults engaged in jumping sports or Sinding Larsen Johansson disease in children. A history of acute knee trauma and joint effusion frequently identifies ligament injuries, patellar dislocations or meniscal tears. Tenderness and swelling around the tibial tuberosity in adolescents indicate Osgood-Schlatter disease. Sensations of the patellar movement or popping out may suggest patellar instability or subluxation, mainly during rotational activities.

Prolonged morning stiffness ( $>30 \mathrm{~min}$ ), simultaneous involvement of several joints or tendons and joint swelling may be a presentation of systemic rheumatologic joint disease. ${ }^{102}$

\section{Management}

Despite the high prevalence, chronicity and burden, PFP continues to be one of the most difficult musculoskeletal conditions managed by medical professionals. ${ }^{120}$ It is evident that greater pain severity and longer symptom duration are indicators of poor prognosis. So, early efficient intervention may be crucial to limit the long-term effects of the condition. ${ }^{121}$

Many possible interventions are recommended by sports medicine practitioners for athletes with PFP; however, no well-established guidelines exist for management of the symptoms. ${ }^{122}$

Due to the multifactorial nature of PFP, the clinical approach should be individualized, and the contribution of different risk factors, including local, proximal (trunk and hip) and distal (foot) factors, should be considered and managed accordingly. ${ }^{121,123}$ This approach may add to the treatment effects on pain and function in patients. ${ }^{123}$ The physicians can use patient education leaflet during management. ${ }^{124}$

There is general agreement that nonsurgical interventions are the primary choice for PFP treatment. However, in order to select sound choices for the best management, practitioners need up-to-date, high-quality evidence. ${ }^{121}$

In this part, we aim to discuss about the most common interventions, according to the existing evidence.

\section{Relative rest and activity modification}

In athletes in whom overuse may play a more significant role, the impact of rest will be more evident. In an acute injury, relative rest will permit the tissue to heal and the symptoms will diminish. In more chronic cases, the physiologic responses may cause daily activities to surpass the pain threshold. This situation leads to a considerable clinical challenge and needs sound patient education to avoid painful joint loading. ${ }^{125}$ 


\section{Exercise}

There is consistent evidence that exercise therapy for PFP may result in clinically important reduction of pain in the short, medium and long terms; improvement in functional ability in the medium and long terms, as well as enhancing longterm recovery. ${ }^{126} \mathrm{Also}$, it has been shown to be cost-effective and is the treatment of choice, especially in young adults. ${ }^{127}$ However, the best mode of exercise therapy is unknown. ${ }^{128}$

There is inadequate information to compare the relative effects of exercise versus other conservative interventions, either unimodal (e.g., taping) or multimodal (combinations of interventions that may include different exercises). ${ }^{128}$

The low-quality existing evidence for comparisons of various exercises is not enough to draw conclusions on the relative results of supervised versus home-based exercises, open versus closed kinetic chain exercises, high- versus low-intensity exercises, hip versus knee exercises, and different variants of closed chain exercises and proprioceptive neuromuscular facilitation stretching and aerobic exercise versus classic stretching and quadriceps exercises. Combining hip and knee exercises is more successful to reduce pain and improve function in the short, medium and long terms, and this combination should be used in preference to knee exercises alone. ${ }^{126}$

There is a lack of high-quality evidence on the exercise medium (land versus water) and the duration of exercises. ${ }^{128}$

Nowadays, considerable debate exists on the specific exercises, target muscles and duration of an ideal exercise program for patients with PFP. ${ }^{129}$ Both strengthening and stretching exercises are recommended in exercise therapy. Nonetheless, assessment of individual risk factors may determine the proper combination of different exercises. ${ }^{123}$

\section{Strengthening}

A meta-analysis of randomized controlled trials (RCTs) showed that positive results were apparent with strengthening exercises, particularly knee extension, squats, stationary cycling, static quadriceps, active straight-leg raise, leg press and step-up and step-down exercises. The current evidence supports a prescription of daily exercises of two to four sets of $\geq 10$ repetitions over a period of $\geq 6$ weeks. ${ }^{130}$

A systematic review of conservative interventions for PFP from 2000 to 2010 deduced that both weight-bearing and non-weight-bearing quadriceps-strengthening exercises are useful for pain reduction. ${ }^{131}$ Although practitioners may prefer weight-bearing exercises to increase the functional activity, the use of non-weight-bearing exercise may be equally valuable, mostly for patients with noticeable quadriceps weakness. One important factor emphasized in recent reviews is that exercises should be pain free, ${ }^{131}$ and applying heavy resistance to the quadriceps will likely perpetuate or aggravate the condition. ${ }^{132}$

Considering the biomechanical stresses at the patellofemoral joint during exercise, it is better to prescribe nonweight-bearing and weight-bearing exercises at $90^{\circ}-45^{\circ}$ and $45^{\circ}-0^{\circ}$ of knee flexion, respectively. ${ }^{125}$

Strengthening program should focus particularly on the vastus medialis oblique, hip abductors and external rotators, as well as core stability training. ${ }^{132,133}$

Although hip exercises have been recommended for the strengthening purpose (i.e., three sets of 10-15 repetitions), there is an indication that muscle endurance also needs to be increased. So, practitioners should consider higher repetitions of sets (i.e., three sets of 20-30 repetitions), in particular, for PFP patients who are involved in more demanding sports such as running and jumping. ${ }^{125}$

\section{Stretching}

Stretching of the hamstring, quadriceps, iliopsoas, gastrocnemius and iliotibial band muscles has been studied for PFP. Theoretically, tight hamstrings, gastrocnemius or iliotibial band muscles may increase the patellofemoral joint reaction forces in full knee extension, whereas tight quadriceps or iliopsoas could cause the same in full flexion. ${ }^{134}$ Lower extremity stretching alone or combined with strengthening exercises or other interventions may improve PFP symptoms in up to $60 \%$ of patients. ${ }^{120,122}$ Proprioceptive neuromuscular facilitation stretching techniques such as contract-relax may be more effective than traditional static or ballistic stretching exercises. ${ }^{135}$ Stretching exercises are recommended as a part of the conservative management of PFP. ${ }^{125}$

In the case of hamstring tightness, patients are trained to perform three alternating repetitions of four passive stretching exercises, and all stretching repetitions will be held for $15 \mathrm{~s}(12 \times 15 \mathrm{~s})$. This program will continue until the end of the 12-week program. ${ }^{136}$ In patients with hip flexor tightness, the stretching comprises passive modified lunge stretches and active prone leg lifts with the knee bent. Both stretches are done for 10 repetitions each in a single daily session and each stretch held for $30 \mathrm{~s}$, with up to a 30-s rest period between repetitions. ${ }^{114,137}$ To address iliotibial band, common standing stretches in three positions of upright standing, overhead clasped hands and diagonally lowered arms are performed. ${ }^{114,138}$ In the case of gastrocnemius tightness, static stretching in forward lunge position is advised. Patients are 
taught to hold the static stretch for $60 \mathrm{~s}$ and complete two repetitions, for a total of $120 \mathrm{~s}$ of stretch during each session. Each session is performed on a daily basis over a 12-week period. ${ }^{114,139,140}$

\section{Patellar taping}

Recent systematic reviews have represented conflicting conclusions regarding the use of patellar taping for PFP. A meta-analysis by Warden et al concluded that a clinically significant reduction in chronic knee pain happens with medially directed tape. ${ }^{141}$ In contrast, a 2012 Cochrane review showed that there was no statistically or clinically significant difference in pain scores on comparing taping with no taping at the end of the treatment period. ${ }^{142}$ Another study demonstrated that taping has minimal effect in management of long-term PFP symptoms; however, clinicians may use patellar taping as a short-term intervention to allow patients to perform pain-free exercise. ${ }^{131}$

A systematic review by Barton et al. concluded that tailored patellar taping immediately reduces pain with a large effect, while other techniques have only small (untailored medial patellar taping) or negligible (Kinesio Tape) effects on pain in the immediate term. The authors recommend patellar taping to control lateral patellar tilt, translation and spin, with the goal of providing at least $50 \%$ pain reduction. The proposed mechanisms for effectiveness of patellar taping include facilitation of earlier vastus medialis oblique onset and enhanced knee function capability during functional tasks. ${ }^{143}$ There is minimal evidence that taping significantly adjusts patellar alignment; however, it may increase the patellofemoral contact area, leading to a decrease in pain. ${ }^{125}$

\section{Knee brace}

Similar to taping, existing evidence has achieved conflicting conclusions about the outcomes of patellofemoral bracing. Overall, there is moderate evidence that knee braces have no additional benefit over exercise therapy on pain and function, and there is also moderate evidence for no significant difference in efficiency between knee braces and exercise therapy versus placebo knee braces and exercise therapy. ${ }^{144}$ Nevertheless, some findings suggest that the Protonics knee brace may be an effective intervention for pain reduction. However, the exact mechanism for improvement is still unclear. ${ }^{131}$ Another study showed that the use of a medially directed realignment brace may result in better outcomes in patients with PFP than exercise alone after 6 and 12 weeks of treatment, but this positive effect reduced after 1 year of follow-up. ${ }^{145}$

A similar study also showed that patellar bracing may alleviate the symptoms of PFP. ${ }^{146}$ Although the exact mechanisms of these positive outcomes are not obvious, they may be the result of redistributed patellar stress, increased proprioceptive input and improved neuromuscular control. ${ }^{131}$ As a conclusion, patellar braces should only be used as an adjunct to other interventions; but to find a definitive answer to this clinical question, the heterogeneity of studies, the variety of braces and the quality of outcome assessment should be borne in mind. ${ }^{125}$

\section{Foot orthosis}

There is inadequate and sometimes conflicting evidence regarding the prescription of foot orthosis as an effective intervention for PFP. ${ }^{125,144}$

A systematic review concluded that there is limited evidence for the use of prefabricated foot orthosis for shortterm improvements in PFP. This review also reported that physiotherapy combined with prefabricated foot orthosis is more effective than foot orthosis alone. ${ }^{147}$

According to the 2016 consensus statement from the Fourth International Patellofemoral Pain Research Retreat, foot orthosis was recommended for short-term pain relief in patients with PFP.

However, it should be emphasized that the average pain reduction may be deemed to lack clinical significance, as a result of considerable individual variability in response. ${ }^{148}$ The cardinal point is that foot orthosis may not be helpful for all patients with PFP, and identifying those most likely to benefit from foot orthosis is important. Published studies have described clinical characteristics that can be used to predict success with foot orthosis intervention, including greater midfoot mobility, ${ }^{149}$ less ankle dorsiflexion and immediate improvements in PFP, when performing a single-leg squat with foot orthosis. ${ }^{150}$

\section{Physical modalities}

Systematic reviews and RCTs have demonstrated a lack of supportive evidence for the use of physical agents such as therapeutic ultrasound, phonophoresis, iontophoresis, transcutaneous electrical nerve stimulation, mediumfrequency neuromuscular electrical stimulation, low-level laser, extracorporeal shock-wave therapy, electromyographic biofeedback and massage therapies. ${ }^{102,125,151,152}$ There is little justification for using these modalities alone for PFP patients. ${ }^{102,126}$ However, despite the lack of clear evidence 
currently, cryotherapy is still recommended as a part of the conservative treatment for PFP. ${ }^{125}$

\section{Pharmacotherapy}

Drugs commonly used for PFP include simple analgesics such as aspirin or acetaminophen and nonsteroidal antiinflammatory drugs (NSAIDs). A Cochrane review of drug therapy for PFP found no important differences in clinical symptoms comparing aspirin with placebo and limited evidence for the efficacy of NSAIDs for short-term pain reduction. Another Cochrane review showed that topical NSAIDs are as effective as oral NSAIDs for pain relief in chronic musculoskeletal pain. ${ }^{153}$ However, NSAIDs may not be recommended due to the absence of a histologic inflammatory response in many PFP cases as well as existing concerns regarding their possible adverse effects on normal healing response of muscles and tendons. Short courses of NSAIDs may be helpful when other modalities such as exercise and analgesics have failed or pain control is necessary for performing the exercise program. ${ }^{125}$

\section{Surgery}

Surgery is the last alternative for PFP and appears to be inadequate. This is emphasized by an RCT that showed no additional improvement in PFP symptoms and function over 9 months after surgery. ${ }^{121}$ Open, arthroscopic and percutaneous techniques have been described as the surgical options. Surgery is usually reserved for refractory cases nonresponsive to conservative treatment. In cautiously selected patients, surgery may be successful, although failure rates of $20 \%-30 \%$ have been reported. ${ }^{125}$ In some selected cases such as serious malalignment (femoral torsional deformity and so on), patella alta or lateral patellar compression syndrome, good outcomes were reported. ${ }^{154-156}$

\section{Other therapies}

Acupuncture and dry needling have been suggested as useful interventions for PFP. Limited evidence revealed a statistically significant pain reduction in the medium term following acupuncture. ${ }^{125}$ Sclerotherapy and prolotherapy injections are among other proposed interventions, although no high-quality evidence exists for their use. ${ }^{125}$ There is limited evidence that injection of Botulinum toxin type A to the distal region of vastus lateralis muscle may increase the activation of vastus medialis. ${ }^{157}$ Patellofemoral, knee and lumbar mobilization or manipulation has been proposed as alternatives, but are not recommended according to the current evidence. ${ }^{126}$

\section{Multimodal approach}

According to the recent literature on PFPS and its specific treatment recommendations, multimodal approach is highly recommended to reduce pain in athletes with PFP in the short and medium terms. ${ }^{126}$ Combined program is the most effective and strongly supported treatment for patients with PFP and includes strength training of weak muscles, stretching of tight muscles and adjunctive therapies such as taping, bracing and foot orthosis, if applicable. ${ }^{122}$ Sports medicine practitioners should particularly assess local, proximal and distal risk factors and use individualized multimodal approach. ${ }^{121,132}$ The algorithmic approach is summarized in Figure 8.

\section{Prognosis}

A substantial proportion of individuals with PFP have an unfavorable recovery over 12 months, irrespective of the intervention. Duration of PFP $>2$ months is the most consistent predictor of poor long-term prognosis, along with a score of $<70$ on the anterior knee pain scale. Those who report higher levels of usual/resting or worst/activity-related pain should also be flagged as potentially having a poor 12-month prognosis. Sports medicine practitioners should promote education regarding the natural history and importance of early intervention for PFP, and prescribe interventions with known efficacy in reducing PFP, in order to maximize the prognosis. ${ }^{158}$

\section{Return to sport}

Athletes may be concerned regarding the time of their return to sport. It is especially true for elite athletes who may plan to participate in important sport events. However, sports medicine practitioners should follow the objective criteria to clear the athletes for participation in sports. The athlete can return to sport when the following criteria are met:

- No swelling

- No pain in squatting and in ascending or descending stairs

- Good quadriceps strength (especially vastus medialis obliques)

- Proper hamstring flexibility

- Normal gait biomechanics

- Proper core stability strength

- Good performance in challenging functional tests (vertical jumping, anteromedial lunge, step-down, single-leg press, and balance and reach tests)

- The patient feeling that he/she is ready and has confidence in the injured knee $\mathrm{e}^{3,125,159}$ 


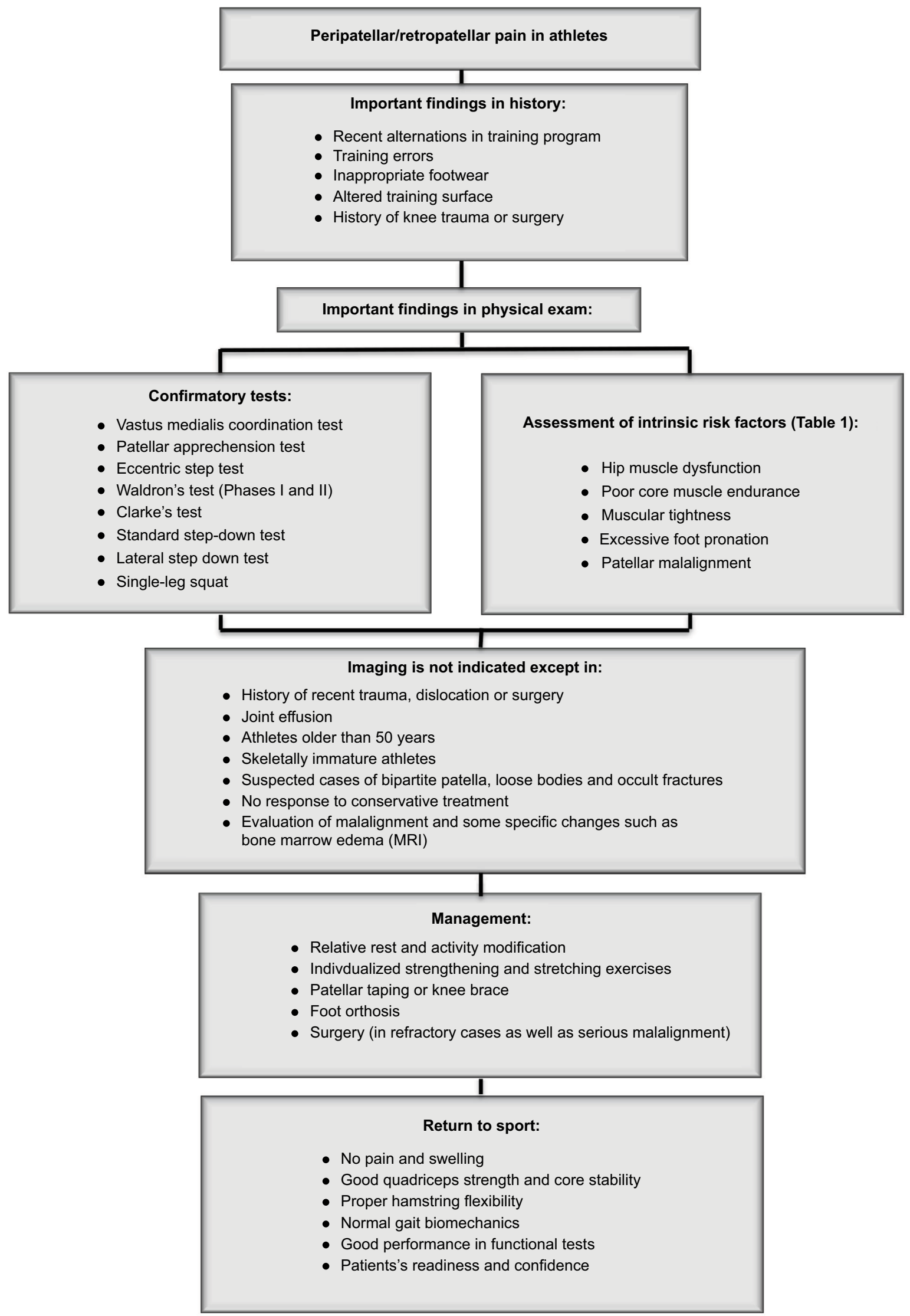

Figure 8 Practical algorithmic approach to diagnosis and treatment of patellofemoral pain in athletes.

Abbreviation: MRI, magnetic resonance imaging. 


\section{Acknowledgments}

The authors would like to thank Dr Reza Mazaheri and Dr Aabolfazl Hashempour for their assistance in preparation of the photos. Consent has been obtained for the patient photos to be used in this study.

\section{Disclosure}

The authors report no conflicts of interest in this work.

\section{References}

1. Witvrouw E, Werner S, Mikkelsen C, Van Tiggelen D, Vanden Berghe L, Cerulli G. Clinical classification of patellofemoral pain syndrome: guidelines for non-operative treatment. Knee Surg Sports Traumatol Arthrosc. 2005;13(2):122-130.

2. Loudon JK, Gajewski B, Goist-Foley HL, Loudon KL. The effectiveness of exercise in treating patellofemoral-pain syndrome. $J$ Sport Rehabil. 2004;13(4):323-342.

3. Witvrouw E, Lysens R, Bellemans J, Cambier D, Vanderstraeten G. Intrinsic risk factors for the development of anterior knee pain in an athletic population. A two-year prospective study. Am J Sports Med. 2000;28(4):480-489.

4. Kannus $P$, Aho H, Järvinen M, Nttymäki S. Computerized recording of visits to an outpatient sports clinic. Am J Sports Med. 1987;15(1):79-85.

5. Devereaux MD, Lachmann SM. Patello-femoral arthralgia in athletes attending a sports injury clinic. Br J Sports Med. 1984;18(1):18-21.

6. Witvrouw E, Callaghan MJ, Stefanik JJ, et al. Patellofemoral pain: consensus statement from the 3rd International Patellofemoral Pain Research Retreat held in Vancouver, September 2013. Br J Sports Med. 2014;48(6):411-414.

7. Natri A, Kannus P, Järvinen M. Which factors predict the long-term outcome in chronic patellofemoral pain syndrome? A 7-yr prospective follow-up study. Med Sci Sports Exerc. 1998;30(11):1572-1577.

8. Baquie P, Brukner P. Injuries presenting to an Australian sports medicine centre: a 12-month study. Clin J Sport Med. 1997;7(1):28-31.

9. LaBella C. Patellofemoral pain syndrome: evaluation and treatment. Prim Care. 2004;31(4):977-1003.

10. DeHaven KE, Lintner DM. Athletic injuries: comparison by age, sport, and gender. Am J Sports Med. 1986;14(3):218-224.

11. Cumps E, Verhagen E, Meeusen R. Prospective epidemiological study of basketball injuries during one competitive season: ankle sprains and overuse knee injuries. J Sports Sci Med. 2007;6(2):204-211.

12. Leppänen M, Pasanen K, Kujala UM, Parkkari J. Overuse injuries in youth basketball and floorball. Open Access J Sports Med. 2015;6:173-179.

13. Briner WW, Kacmar L. Common injuries in volleyball. Sports Med. 1997;24(1):65-71.

14. Nejati P, Forogh B, Moeineddin R, Baradaran HR, Nejati M. Patellofemoral pain syndrome in Iranian female athletes. Acta Med Iran. 2011;49(3):169.

15. van Mechelen W. Running injuries. Sports Med. 1992;14(5):320-335.

16. van Gent BR, Siem DD, van Middelkoop M, van Os TA, BiermaZeinstra SS, Koes BB. Incidence and determinants of lower extremity running injuries in long distance runners: a systematic review. $\mathrm{Br} \mathrm{J}$ Sports Med. 2007;41(8):469-480; discussion 480.

17. Taunton JE, Ryan MB, Clement D, McKenzie DC, Lloyd-Smith D, Zumbo B. A retrospective case-control analysis of 2002 running injuries. Br J Sports Med. 2002;36(2):95-101.

18. Fulkerson JP. Diagnosis and treatment of patients with patellofemoral pain. Am J Sports Med. 2002;30(3):447-456.

19. Fairbank J, Pynsent P, van Poortvliet JA, Phillips H. Mechanical factors in the incidence of knee pain in adolescents and young adults. Bone Joint J. 1984;66(5):685-693.

20. Blond L, Hansen L. Patellofemoral pain syndrome in athletes: a 5.7year retrospective follow-up study of 250 athletes. Acta Orthop Belg. 1998;64(4):393-400.
21. Nimon G, Murray D, Sandow M, Goodfellow J. Natural history of anterior knee pain: a 14-to 20-year follow-up of nonoperative management. J Pediatr Orthop. 1998;18(1):118-122.

22. Myer GD, Ford KR, Barber Foss KD, et al. The incidence and potential pathomechanics of patellofemoral pain in female athletes. Clin Biomech (Bristol, Avon). 2010;25(7):700-707.

23. Utting M, Davies G, Newman J. Is anterior knee pain a predisposing factor to patellofemoral osteoarthritis? Knee. 2005;12(5):362-365.

24. Conchie H, Clark D, Metcalfe A, Eldridge J, Whitehouse M. Adolescent knee pain and patellar dislocations are associated with patellofemoral osteoarthritis in adulthood: a case control study. Knee. 2016;23(4):708-711.

25. Myer GD, Ford KR, Di Stasi SL, Foss KDB, Micheli LJ, Hewett TE. High knee abduction moments are common risk factors for patellofemoral pain (PFP) and anterior cruciate ligament (ACL) injury in girls: is PFP itself a predictor for subsequent ACL injury? Br J Sports Med. 2015;49(2):118-122.

26. Doberstein ST, Romeyn RL, Reineke DM. The diagnostic value of the Clarke sign in assessing chondromalacia patella. J Athl Train. 2008;43(2):190-196.

27. Thomee R, Augustsson J, Karlsson J. Patellofemoral pain syndrome: a review of current issues. Sports Med. 1999;28(4):245-262.

28. Crossley KM, Stefanik JJ, Selfe J, et al. 2016 Patellofemoral pain consensus statement from the 4th International Patellofemoral Pain Research Retreat, Manchester. Part 1: terminology, definitions, clinical examination, natural history, patellofemoral osteoarthritis and patient-reported outcome measures. Br J Sports Med. 2016;50(14): 839-843.

29. Powers CM. Rehabilitation of patellofemoral joint disorders: a critical review. J Orthop Sports Phys Ther. 1998;28(5):345-354.

30. Davis IS, Powers CM. Patellofemoral pain syndrome: proximal, distal, and local factors, an international retreat, April 30-May 2, 2009, Fells Point, Baltimore, MD. J Orthop Sports Phys Ther. 2010;40(3): A1-A16.

31. Powers CM, Bolgla LA, Callaghan MJ, Collins N, Sheehan FT. Patellofemoral Pain: Proximal, Distal, and Local Factors-2nd International Research Retreat, August 31-September 2, 2011, Ghent, Belgium. JOSPT, Inc. JOSPT, 1033 North Fairfax Street, Suite 304, Alexandria, VA 22134-1540; 2012.

32. Collado H, Fredericson M. Patellofemoral pain syndrome. Clin Sports Med. 2010;29(3):379-398.

33. Hart H, Ackland D, Pandy M, Crossley K. Quadriceps volumes are reduced in people with patellofemoral joint osteoarthritis. Osteoarthritis Cartilage. 2012;20(8):863-868.

34. Dixit S, DiFiori JP, Burton M, Mines B. Management of patellofemoral pain syndrome. Am Fam Phys. 2007;75(2):194-202.

35. Lankhorst NE, Bierma-Zeinstra SM, van Middelkoop M. Risk factors for patellofemoral pain syndrome: a systematic review. J Orthop Sports Phys Ther. 2012;42(2):81-94.

36. Ageberg E, Zätterström R, Moritz U. Stabilometry and one-leg hop test have high test-retest reliability. Scand J Med Sci Sports. 1998;8(4):198-202.

37. Steinkamp LA, Dillingham MF, Markel MD, Hill JA, Kaufman KR. Biomechanical considerations in patellofemoral joint rehabilitation. Am J Sports Med. 1993;21(3):438-444.

38. Rice J, Bennett G, Ruhling R. Comparison of two exercises on VMO and VL EMG activity and force production. Isokinet Exerc Sci. 1995;5(2):61-67.

39. Insall J. Current concepts review: patellar pain. J Bone Joint Surg. 1982;64(1):147.

40. Robinson RL, Nee RJ. Analysis of hip strength in females seeking physical therapy treatment for unilateral patellofemoral pain syndrome. J Orthop Sports Phys Ther. 2007;37(5):232-238.

41. Prins MR, van der Wurff P. Females with patellofemoral pain syndrome have weak hip muscles: a systematic review. Aust J Physiother. 2009;55(1):9-15.

42. Wilson E. Core stability: assessment and functional strengthening of the hip abductors. Strength Condition J. 2005;27(2):21-23. 
43. Presswood L, Cronin J, Keogh JWL, Whatman C. Gluteus medius: applied anatomy, dysfunction, assessment, and progressive strengthening. Strength Condition J. 2008;30(5):41.

44. Reiman MP, Goode AP, Hegedus EJ, Cook CE, Wright AA. Diagnostic accuracy of clinical tests of the hip: a systematic review with metaanalysis. Br J Sports Med. 2013;47(14):893-902.

45. Earl JE, Hoch AZ. A Proximal strengthening program improves pain, function, and biomechanics in women with patellofemoral pain syndrome. Am J Sport Med. 2011;39(1):154-163.

46. Ferber R, Bolgla L, Earl-Boehm JE, Emery C, Hamstra-Wright K. Strengthening of the hip and core versus knee muscles for the treatment of patellofemoral pain: a multicenter randomized controlled trial. J Athl Train. 2015;50(4):366-377.

47. McGill SM, Childs A, Liebenson C. Endurance times for low back stabilization exercises: clinical targets for testing and training from a normal database. Archiv Phys Med Rehabil. 1999;80(8):941-944.

48. Waryasz GR, McDermott AY. Patellofemoral pain syndrome (PFPS): a systematic review of anatomy and potential risk factors. Dyn Med. 2008;7:9

49. White LC, Dolphin P, Dixon J. Hamstring length in patellofemoral pain syndrome. Physiotherapy. 2009;95(1):24-28.

50. Piva SR, Goodnite EA, Childs JD. Strength around the hip and flexibility of soft tissues in individuals with and without patellofemoral pain syndrome. J Orthop Sports Phys Ther. 2005;35(12):793-801.

51. Davis DS, Quinn RO, Whiteman CT, Williams JD, Young CR. Concurrent validity of four clinical tests used to measure hamstring flexibility. $J$ Strength Cond Res. 2008;22(2):583-588.

52. Davis DS, Ashby PE, McCale KL, McQuain JA, Wine JM. The effectiveness of 3 stretching techniques on hamstring flexibility using consistent stretching parameters. J Strength Cond Res. 2005;19(1): 27-32.

53. Youdas JW, Krause DA, Hollman JH, Harmsen WS, Laskowski E. The influence of gender and age on hamstring muscle length in healthy adults. J Orthop Sports Phys Ther. 2005;35(4):246-252.

54. Fredriksen H, Dagfinrud H, Jacobsen V, Maehlum S. Passive knee extension test to measure hamstring muscle tightness. Scand J Med Sci Sports. 1997;7(5):279-282.

55. Gabbe B, Bennell K, Wajswelnerc H, Finch C. Reliability of common lower extremity musculoskeletal screening tests. Phys Ther Sport 2004;5(2):90-97.

56. Tyler TF, Nicholas SJ, Mullaney MJ, McHugh MP. The role of hip muscle function in the treatment of patellofemoral pain syndrome. Am J Sports Med. 2006;34(4):630-636.

57. Post WR. Patellofemoral pain: results of nonoperative treatment. Clin Orthop Relat Res. 2005(436):55-59.

58. Bartlett MD, Wolf LS, Shurtleff DB, Stahell LT. Hip flexion contractures: a comparison of measurement methods. Arch Phys Med Rehabil. 1985;66(9):620-625.

59. Harvey D. Assessment of the flexibility of elite athletes using the modified Thomas test. Br J Sports Med. 1998;32(1):68-70.

60. Winslow J, Yoder E. Patellofemoral pain in female ballet dancers: correlation with iliotibial band tightness and tibial external rotation. J Orthop Sports Phys Ther. 1995;22(1):18-21.

61. Puniello MS. Iliotibial band tightness and medial patellar glide in patients with patellofemoral dysfunction. J Orthop Sports Phys Ther. 1993;17(3):144-148.

62. Hudson Z, Darthuy E. Iliotibial band tightness and patellofemoral pain syndrome: a case-control study. Man Ther. 2009;14(2):147-151.

63. Herrington L, Rivett N, Munroa S. The relationship between patella position and length of the iliotibial band as assessed using Ober's test. Man Ther. 2006;11(3):182-186.

64. Wang TG, Jan MH, Lin KH, Wang HK. Assessment of stretching of the iliotibial tract with Ober and modified Ober tests: an ultrasonographic study. Archiv Phys Med Rehabil. 2006;87(10):1407-1411.

65. Melchione WE SM. Reliability of measurements obtained by use of an instrument designed to indirectly measure iliotibial band length. J Orthop Sports Phys Ther. 1993;18(3):511-515.
66. Reese N, Bandy W. Use of an inclinometer to measure flexibility of the iliotibial band using the Ober test and the modified Ober test: differences in magnitude and reliability of measurements. J Orthop Sports Phys Ther. 2003;33(6):326-330.

67. Sanchis-Alfonso V, Rosello-Sastre E, Martinez-Sanjuan V. Pathogenesis of anterior knee pain syndrome and functional patellofemoral instability in the active young. Am J Knee Surg. 1999;12(1):29-40.

68. Dennis RJ, Finch CF, Elliottc BC, Farhart PJ. The reliability of musculoskeletal screening tests used in cricket. Phys Ther Sport. 2008;9(1):25-33.

69. Bennell KL, Talbot RC, Wajswelner H, Techovanich W, Kelly DH, Hall AJ. Intra-rater and inter-rater reliability of a weight-bearing lunge measure of ankle dorsiflexion. Aust J Physiother. 1998;44(3):175-180.

70. Barton CJ, Bonanno D, Levinger P, Menz HB. Foot and ankle characteristics in patellofemoral pain syndrome: a case control and reliability study. J Orthop Sports Phys Ther. 2010;40(5):286-296.

71. Powers CM, Maffucci R, Hampton S. Rearfoot posture in subjects with patellofemoral pain. J Orthop Sports Phys Ther. 1995;22(4):155-160.

72. Barton CJ, Levinger P, Crossley KM, Webster KE, Menz HB. Relationships between the Foot Posture Index and foot kinematics during gait in individuals with and without patellofemoral pain syndrome. J Foot Ankle Res. 2011;4:10.

73. Redmond A, Crosbie J, Ouvrier R. Development and validation of a novel rating system for scoring standing foot posture: the Foot Posture Index. Clin Biomech (Bristol, Avon). 2006;21(1):89-98.

74. Redmond AC, Crane YZ, Menz HB. Normative values for the foot posture index. J Foot Ankle Res. 2008;1(1):6.

75. Kannus P, Niittymaki S. Which factors predict outcome in the nonoperative treatment of patellofemoral pain syndrome? A prospective follow-up study. Med Sci Sports Exerc. 1994;26(3):289-296.

76. Brady RJ, Dean JB, Skinner TM, Gross MT. Limb length inequality: clinical implications for assessment and intervention. J Orthop Sports Phys Ther. 2003;33(5):221-234.

77. Gogia PP, Braatz JH. Validity and reliability of leg length measurements. J Orthop Sports Phys Ther. 1986;8(4):185-188.

78. Hoyle D, Latour M, Bohannon R. Intraexaminer, interexaminer, and interdevice comparability of leg length measurements obtained with measuring tape and metrecom. J Orthop Sports Phys Ther. 1991;14(6):263-268.

79. Fredericson M, Yoon K. Physical examination and patellofemoral pain syndrome. Am J Phys Med Rehabil. 2006;85(3):234-243.

80. Haim A, Yaniv M, Dekel S, Amir H. Patellofemoral pain syndrome: validity of clinical and radiological features. Clin Orthop Relat Res. 2006;451:223-228.

81. Watson CJ, Propps M, Galt W, Redding A, Dobbs D. Reliability of McConnell's classification of patellar orientation in symptomatic and asymptomatic subjects. J Orthop Sports Phys Ther. 1999;29(7): 378-385; discussion 386-393.

82. Powers CM, Mortenson S, Nishimoto D, Simon D. Criterion-related validity of a clinical measurement to determine the medial/lateral component of patellar orientation. J Orthop Sports Phys Ther. 1999;29(7): 372-377.

83. Watson CJ, Leddy HM, Dynjan TD, Parham JL. Reliability of the lateral pull test and tilt test to assess patellar alignment in subjects with symptomatic knees: student raters. J Orthop Sports Phys Ther. 2001;31(7):368-374.

84. Smith TO, Davies L, Donell ST. The reliability and validity of assessing medio-lateral patellar position: a systematic review. Man Ther. 2009;14(4):355-362.

85. al-Rawi Z, Nessan AH. Joint hypermobility in patients with chondromalacia patellae. Br J Rheumatol. 1997;36(12):1324-1327.

86. Boyle KL, Witt P, Riegger-Krugh C. Intrarater and interrater reliability of the beighton and horan joint mobility index. J Athl Train. 2003;38(4):281-285.

87. Juul-Kristensen B, Rogind H, Jensen DV, Remvig L. Inter-examiner reproducibility of tests and criteria for generalized joint hypermobility and benign joint hypermobility syndrome. Rheumatology (Oxford). 2007;46(12):1835-1841. 
88. Remvig L, Jensen DV, Ward RC. Are diagnostic criteria for general joint hypermobility and benign joint hypermobility syndrome based on reproducible and valid tests? A review of the literature. J Rheumatol. 2007;34(4):798-803.

89. Lun V, Meeuwisse W, Stergiou P, Stefanyshyn D. Relation between running injury and static lower limb alignment in recreational runners. Br J Sports Med. 2004;38(5):576-580.

90. Kraus VB, Vail TP, Worrell T, McDaniel G. A comparative assessment of alignment angle of the knee by radiographic and physical examination methods. Arthritis Rheumatol. 2005;52(6):1730-1735.

91. Macri EM, Stefanik JJ, Khan KK, Crossley KM. Is tibiofemoral or patellofemoral alignment or trochlear morphology associated with patellofemoral osteoarthritis? A systematic review. Arthritis Care Res. 2016;68(10):1453-1470.

92. Davies AP, Costa ML, Donnell ST, Glasgow MM, Shepstone L. The sulcus angle and malalignment of the extensor mechanism of the knee. Bone Joint J. 2000;82(8):1162-1166.

93. Smith T, Cogan A, Patel S, Shakokani M, Toms A, Donell S. The intra-and inter-rater reliability of X-ray radiological measurements for patellar instability. Knee. 2013;20(2):133-138.

94. Duran S, Cavusoglu M, Kocadal O, Sakman B. Association between trochlear morphology and chondromalacia patella: an MRI study. Clin Imaging. 2017;41:7-10.

95. Baker V, Bennell K, Stillman B, Cowan S, Crossley K. Abnormal knee joint position sense in individuals with patellofemoral pain syndrome. J Orthop Res. 2002;20(2):208-214.

96. Callaghan MJ. What does proprioception testing tell us about patellofemoral pain? Man Ther. 2011;16(1):46-47.

97. Stillman BC. An investigation of the clinical assessment of joint position sense [PhD thesis]. The University of Melbourne, Australia; 2000.

98. Thijs Y, Van Tiggelen D, Roosen P, De Clercq D, Witvrouw E. A prospective study on gait-related intrinsic risk factors for patellofemoral pain. Clin J Sport Med. 2007;17(6):437-445.

99. De Cock A, De Clercq D, Willems T, Witvrouw E. Temporal characteristics of foot roll-over during barefoot jogging: reference data for young adults. Gait Posture. 2005;21(4):432-439.

100. Manske RC, Davies GJ. Examination of the patellofemoral joint. Int J Sports Phys Ther. 2016;11(6):831.

101. Post WR. Current concepts clinical evaluation of patients with patellofemoral disorders. Arthroscopy. 1999;15(8):841-851.

102. Crossley KM, Callaghan MJ, van Linschoten R. Patellofemoral pain. BMJ. 2015;351:h3939.

103. Nunes GS, Stapait EL, Kirsten MH, de Noronha M, Santos GM. Clinical test for diagnosis of patellofemoral pain syndrome: systematic review with meta-analysis. Phys Ther Sport. 2013;14(1):54-59.

104. Malanga GA, Andrus S, Nadler SF, McLean J. Physical examination of the knee: a review of the original test description and scientific validity of common orthopedic tests. Arch Phys Med Rehabil. 2003;84(4):592-603

105. Nijs J, Van Geel C, Van der auwera C, Van de Velde B. Diagnostic value of five clinical tests in patellofemoral pain syndrome. Man Ther. 2006;11(1):69-77.

106. Cook C, Mabry L, Reiman MP, Hegedus EJ. Best tests/clinical findings for screening and diagnosis of patellofemoral pain syndrome: a systematic review. Physiotherapy. 2012;98(2):93-100.

107. Souza T. The knee. In: Hyde TE, Gengenbach MS, editors. Conservative Management of Sport Injuries. Baltimore, MD: Williams \& Wilkins; 1997:394-395.

108. Selfe J, Harper L, Pedersen I, Breen-Turner J, Waring J. Four outcome measures for patellofemoral joint problems. Part 1: development and validity. Physiotherapy. 2001;87(10):507-515.

109. Selfe J, Harper L, Pedersen I, Breen-Turner J, Waring J. Four outcome measures for patellofemoral joint problems: part 2. Reliability and clinical sensitivity. Physiotherapy. 2001;87(10):516-522.

110. Reider B. The knee. In: Reider B, editor. The Orthopaedic Physical Examination. 2nd ed. Philadelphia, PA: Elsevier Saunders; 2005:201-246.
111. Crossley KM, Zhang W-J, Schache AG, Bryant A, Cowan SM. Performance on the single-leg squat task indicates hip abductor muscle function. Am J Sports Med. 2011;39(4):866-873.

112. Rabin A, Kozol Z, Moran U, Efergan A, Geffen Y, Finestone AS. Factors associated with visually assessed quality of movement during a lateral step-down test among individuals with patellofemoral pain. J Orthop Sports Phys Ther. 2014;44(12):937-946.

113. Nakagawa TH, Moriya ET, Maciel CD, Serrao FV. Trunk, pelvis, hip, and knee kinematics, hip strength, and gluteal muscle activation during a single-leg squat in males and females with and without patellofemoral pain syndrome. J Orthop Sports Phys Ther. 2012;42(6):491-501.

114. Halabchi F, Mazaheri R, Seif Barghi T. Patellofemoral pain syndrome and modifiable intrinsic risk factors; How to assess and address? Asian J Sports Med. 2013;4(2):85-100.

115. Elias DA, White LM. Imaging of patellofemoral disorders. Clin Radiol. 2004;59(7):543-557.

116. Galland O, Walch G, Dejour H, Carret JP. An anatomical and radiological study of the femoropatellar articulation. Surg Radiol Anat. 1990;12(2):119-125.

117. Samim M, Smitaman E, Lawrence D, Moukaddam H. MRI of anterior knee pain. Skeletal Radiol. 2014;43(7):875-893.

118. Tuna BK, Semiz-Oysu A, Pekar B, Bukte Y, Hayirlioglu A. The association of patellofemoral joint morphology with chondromalacia patella: a quantitative MRI analysis. Clin Imaging. 2014;38(4):495-498.

119. Schindler OS. 'The Sneaky Plica' revisited: morphology, pathophysiology and treatment of synovial plicae of the knee. Knee Surg Sports Traumatol Arthrosc. 2014;22(2):247-262.

120. Crossley K, Bennell K, Green S, McConnell J. A systematic review of physical interventions for patellofemoral pain syndrome. Clin J Sport Med. 2001;11(2):103-110.

121. Collins NJ, Bisset LM, Crossley KM, Vicenzino B. Efficacy of nonsurgical interventions for anterior knee pain: systematic review and meta-analysis of randomized trials. Sports Med. 2012;42(1):31-49.

122. Rixe JA, Glick JE, Brady J, Olympia RP. A review of the management of patellofemoral pain syndrome. Phys Sports Med. 2013;41(3):19-28.

123. Halabchi F, Mazaheri R, Mansournia MA, Hamedi Z. Additional effects of an individualized risk factor-based approach on pain and the function of patients with patellofemoral pain syndrome: a randomized controlled trial. Clin J Sport Med. 2015;25(6):478-486.

124. Barton CJ, Rathleff MS. 'Managing my patellofemoral pain': the creation of an education leaflet for patients. BMJ open sport \& exercise medicine. 2016;2(1):e000086.

125. Hiemstra LA, Kerslake S, Irving C. Anterior knee pain in the athlete. Clin Sports Med. 2014;33(3):437-459.

126. Crossley KM, van Middelkoop M, Callaghan MJ, Collins NJ, Rathleff MS, Barton CJ. 2016 Patellofemoral pain consensus statement from the 4th International Patellofemoral Pain Research Retreat, Manchester. Part 2: recommended physical interventions (exercise, taping, bracing, foot orthoses and combined interventions). Br J Sports Med. 2016;50(14):844-852.

127. Roux L. Exercise therapy for patellofemoral pain syndrome costs society less than usual care. Clin J Sport Med. 2011;21(3): 275-276.

128. Van Der Heijden RA, Lankhorst NE, Van Linschoten R, BiermaZeinstra SM, Van Middelkoop M. Exercise for treating patellofemoral pain syndrome: an abridged version of Cochrane systematic review. Eur J Phys Rehabil Med. 2016;52(1):110-133.

129. Rothermich MA, Glaviano NR, Li J, Hart JM. Patellofemoral pain: epidemiology, pathophysiology, and treatment options. Clin Sports Med. 2015;34(2):313-327.

130. Harvie D, O'Leary T, Kumar S. A systematic review of randomized controlled trials on exercise parameters in the treatment of patellofemoral pain: what works? J Multidiscip Healthc. 2011;4:383-392.

131. Bolgla LA, Boling MC. An update for the conservative management of patellofemoral pain syndrome: a systematic review of the literature from 2000 to 2010. Int J Sports Phys Ther. 2011;6(2):112-125. 
132. Fulkerson J. A practical guide to understanding and treating patellofemoral pain. Am J Orthop (Belle Mead, NJ). 2017;46(2):101.

133. Thomson C, Krouwel O, Kuisma R, Hebron C. The outcome of hip exercise in patellofemoral pain: a systematic review. Man Ther. 2016;26:1-30.

134. Al-Hakim W, Jaiswal PK, Khan W, Johnstone D. The non-operative treatment of anterior knee pain. Open Orthop J. 2012;6:320-326.

135. Moyano FR, Valenza M, Martin LM, Caballero YC, Gonzalez-Jimenez E, Demet GV. Effectiveness of different exercises and stretching physiotherapy on pain and movement in patellofemoral pain syndrome: a randomized controlled trial. Clin Rehabil. 2013;27(5):409-417.

136. Sainz de Baranda P, Ayala F. Chronic flexibility improvement after 12 week of stretching program utilizing the ACSM recommendations: hamstring flexibility. Int J Sports Med. 2010;31(6):389-396.

137. Winters MV, Blake CG, Trost JS, et al. Passive versus active stretching of hip flexor muscles in subjects with limited hip extension: a randomized clinical trial. Phys Ther. 2004;84(9):800-807.

138. Fredericson M, White JJ, Macmahon JM, Andriacchi TP. Quantitative analysis of the relative effectiveness of 3 iliotibial band stretches. Arch Phys Med Rehabil. 2002;83(5):589-592.

139. Gajdosik RL, Allred JD, Gabbert HL, Sonsteng BA. A stretching program increases the dynamic passive length and passive resistive properties of the calf muscle-tendon unit of unconditioned younger women. Eur J Appl Physiol. 2007;99(4):449-454.

140. Nakamura M, Ikezoe T, Takeno Y, Ichihashi N. Effects of a 4-week static stretch training program on passive stiffness of human gastrocnemius muscle-tendon unit in vivo. Eur JAppl Physiol. 2012;112(7):2749-2755.

141. Warden SJ, Hinman RS, Watson MA, Avin KG, Bialocerkowski AE, Crossley KM. Patellar taping and bracing for the treatment of chronic knee pain: a systematic review and meta-analysis. Arthritis Care Res. 2008;59(1):73-83.

142. Callaghan M. Patellar taping for patellofemoral pain syndrome in adults. Results from the Cochrane review. J Orthop Sports Phys. 2012;42(6):A53-A54.

143. Barton C, Balachandar V, Lack S, Morrissey D. Patellar taping for patellofemoral pain: a systematic review and meta-analysis to evaluate clinical outcomes and biomechanical mechanisms. Br J Sports Med. 2014;48(6):417-424.

144. Swart NM, van Linschoten R, Bierma-Zeinstra SM, van Middelkoop $M$. The additional effect of orthotic devices on exercise therapy for patients with patellofemoral pain syndrome: a systematic review. $\mathrm{Br}$ J Sports Med. 2012;46(8):570-577.

145. Petersen W, Ellermann A, Rembitzki IV, et al. Evaluating the potential synergistic benefit of a realignment brace on patients receiving exercise therapy for patellofemoral pain syndrome: a randomized clinical trial. Arch Orthop Trauma Surg. 2016;136(7):975-982.
146. Lun VMY, Wiley JP, Meeuwisse WH, Yanagawa TL. Effectiveness of patellar bracing for treatment of patellofemoral pain syndrome. Clin $J$ Sport Med. 2005;15(4):235-240.

147. Barton CJ, Munteanu SE, Menz HB, Crossley KM. The efficacy of foot orthoses in the treatment of individuals with patellofemoral pain syndrome. Sports Med. 2010;40(5):377-395.

148. Collins N, Crossley K, Beller E, Darnell R, McPoil T, Vicenzino B. Foot orthoses and physiotherapy in the treatment of patellofemoral pain syndrome: randomised clinical trial. BMJ. 2008;337:a1735.

149. Vicenzino B, Collins N, Cleland J, McPoil T. A clinical prediction rule for identifying patients with patellofemoral pain who are likely to benefit from foot orthoses: a preliminary determination. BrJ Sports Med. 2010;44(12):862-866.

150. Barton CJ, Menz HB, Crossley KM. Clinical predictors of foot orthoses efficacy in individuals with patellofemoral pain. Med Sci Sports Exerc. 2011;43(9):1603-1610.

151. Lake DA, Wofford NH. Effect of therapeutic modalities on patients with patellofemoral pain syndrome: a systematic review. Sports Health 2011;3(2):182-189.

152. Dos Santos RL, Souza ML, Dos Santos FA. Neuromuscular electric stimulation in patellofemoral dysfunction: literature review. Acta Ortop Bras. 2013;21(1):52-58.

153. Derry S, Moore RA, Rabbie R. Topical NSAIDs for chronic musculoskeletal pain in adults. Cochrane Database Syst Rev. 2012;(9): CD007400.

154. AL-Sayyad MJ, Cameron JC. Functional outcome after tibial tubercle transfer for the painful patella alta. Clin Orthop Relat Res. 2002(396): $152-162$.

155. Dickschas J, Harrer J, Reuter B, Schwitulla J, Strecker W. Torsional osteotomies of the femur. J Orthop Res. 2015;33(3):318-324.

156. Pagenstert G, Wolf N, Bachmann M, et al. Open lateral patellar retinacular lengthening versus open retinacular release in lateral patellar hypercompression syndrome: a prospective double-blinded comparative study on complications and outcome. Arthroscopy. 2012;28(6):788-797.

157. Singer BJ, Silbert BI, Silbert PL, Singer KP. The role of botulinum toxin type a in the clinical management of refractory anterior knee pain. Toxins. 2015;7(9):3388-3404.

158. Collins NJ, Bierma-Zeinstra SM, Crossley KM, van Linschoten RL, Vicenzino B, van Middelkoop M. Prognostic factors for patellofemoral pain: a multicentre observational analysis. Br J Sports Med. 2013;47(4):227-233.

159. Loudon JK, Wiesner D, Goist-Foley HL, Asjes C, Loudon KL. Intrarater reliability of functional performance tests for subjects with patellofemoral pain syndrome. J Athl Train. 2002;37(3):256-261.
Open Access Journal of Sports Medicine

\section{Publish your work in this journal}

The Open Access Journal of Sports Medicine is an international, peer-reviewed, open access journal publishing original research, reports, reviews and commentaries on all areas of sports medicine. The journal is included on PubMed. The manuscript management system is completely online and includes a very quick and fair

\section{Dovepress}

peer-review system. Visit http://www.dovepress.com/testimonials.php to read real quotes from published authors. 